\title{
Re-estimating the Demographic Impact on Health Care Expenditure: Evidence from Taiwan
}

\author{
Yung-Ming Shiu and Mei-Ching Chiu \\ Department of Business Administration, National Cheng Kung University, 1, University Road, \\ Tainan, Taiwan. \\ E-mail: yungming@mail.ncku.edu.tw
}

Unlike prior studies, we consider not only population ageing but also life expectancy as demographic variables that may explain the variations in health care expenditure. Cointegration techniques are employed to re-examine the effect of demographic changes on the Taiwan health care expenditure from 1960 to 2006. We find that the Taiwan health care expenditure, income, population ageing, life expectancy and the number of practicing physicians have statistically significant and long-run economic relationships. All variables have a positive impact on health care expenditure besides life expenditure. Our empirical results support the compression of morbidity hypothesis, suggesting that older people become healthier than in the past and that health care expenditure would decrease with life expectancy. Several implications for policymaking and future research are offered.

The Geneva Papers (2008) 33, 728-743. doi:10.1057/gpp.2008.26

Keywords: health care expenditure; population demographic impact; population ageing; life expectancy; longevity; compression of morbidity

\section{Introduction}

Over the past decades, most developed countries have experienced significant changes in their population structure, with ageing perhaps being the most important change. ${ }^{1}$ There are two possible reasons for this, one is the decline in the birth rate and the other is the natural extension of life expectancy (denoted as LE). Health policymakers are concerned that the increasing numbers of older people will increase the need for health expenditure and most people intuitively believe that such expenditure rises along with LE. Longevity has thus becomes an important issue with regard to health care spending.

In recent years, many studies have extensively examined the determinants of health care expenditure (denoted as HCE) by using macro- or micro-data. At the aggregated level, most research shows that age structure or population ageing has a small or nonsignificant impact on $\mathrm{HCE}^{2}$ At the individual level, some authors argue that population ageing is a red herring that does not deserve the attention it usually receives. They find that population ageing is not the primary driver of $\mathrm{HCE}^{3}$

\footnotetext{
${ }^{1}$ Ryder (1988).

${ }^{2}$ Hitiris and Posnett (1992); Hansen and King (1996); Barros (1998); Gerdtham and Lothgren (2000); Di Matteo (2005); Martins et al. (2006).

${ }^{3}$ Zweifel et al. (1999, 2004); Seshamani and Gray (2004); Stearns and Norton (2004); Dormont et al. (2006).
} 
highlighting instead the important effects of time to death or health status. Notably, when these studies add the time to death proxy to the account, the influence of age on HCE is significantly reduced.

Many previous studies state that the income proxy has a more significant impact than age structure. ${ }^{4}$ However, several investigations still find that there is a significant and positive correlation between the proportion of elderly people and $\mathrm{HCE}^{5}$ In summary, it is difficult to come to any conclusions about the impact of demographics on HCE due to the discordant opinions on population ageing. However, since the LE change would influence the change in health status for aged groups, we add this factor to the HCE model to estimate the complete impact of demographics.

The structure of health care demand is likely to change due to increases in LE and falls in mortality. There are two opposite hypotheses on the impacts of the increase in LE on health care cost with constant medical technology. First is the expansion of the morbidity hypothesis, which assumes that the main effect of medical progress is to prolong the life of those patients who are so sick that they spend most of the additional years in the sickbed. Another is the compression of morbidity hypothesis, which states that an increase in LE, through a drop in the total mortality rate, will even lower per capita HCE. ${ }^{6}$ Most empirical evidence supports the compression of morbidity. Dormont et al. ${ }^{7}$ find that changes in morbidity induce health improvements that more than offset the increase in spending due to population ageing, meaning that longer lives do not necessarily entail rising HCE, and some empirical studies even find that an increase in longevity actually slows the growth in spending. ${ }^{8}$ Furthermore, Michel and Robine ${ }^{9}$ propose a new theory of the ageing population based on a cyclical movement. At first, sicker people survive into old age and disability rises, and then the number of years lived with disability decreases as new cohorts of healthier people enter old age. Finally, the number of years lived with disability increases again when the average age of death rises so much that many people spend their last years at an advanced age burdened by multiple chronic diseases and frailty. Thus co-exist the extension and compression of morbidity and this means that although people live longer it does not entail increasing HCE.

According to the World Population Prospects of the Population Division Department of the United Nations Secretariat (hereafter UNPD), the proportion of the world's population aged 65 and over is expected to rise from 7.3 to 10.5 per cent between 2005 and 2025. Japan has moved from an ageing country to an aged country, with the share of population aged 65 and over rising from 7 to 14 per cent in a period of only 25 years. As shown in Figure 1, the trend of population ageing in Taiwan is similar to that in Japan, and the speed is faster than in the United States, the United Kingdom and France. ${ }^{10}$ As indicated above, LE among the older population has been

\footnotetext{
${ }^{4}$ Newhouse (1977); Gerdtham et al. (1992); O’Connell (1996); Barros (1998).

${ }^{5}$ Hitiris and Posnett (1992); Murthy and Ukpolo (1994, 1995).

${ }^{6}$ Breyer and Felder (2006).

${ }^{7}$ Dormont et al. (2006).

${ }^{8}$ Hodgson (1992); Daviglus et al. (1998); Spillman and Lubitz (2000); Miller (2001); Lubitz et al. (2003).

${ }^{9}$ Michel and Robine (2004).

${ }^{10}$ UNPD (2006).
} 


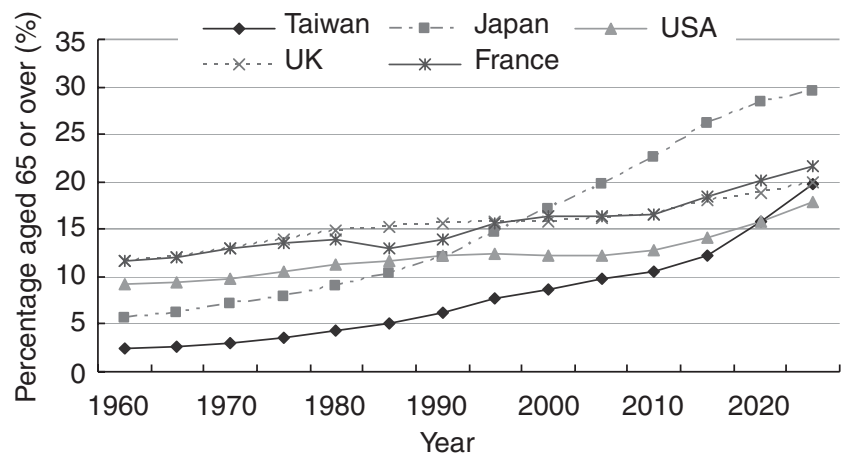

Figure 1. The population ageing of Taiwan, Japan, U.S.A., U.K., and France during 1960-2025. Source: UNPD (2006), TWCEPD (2008), and own calculations.

improving for many decades and some studies show that long life, accompanied by better health, may not cause a significant increase in health care spending. ${ }^{11}$ However, many of the early studies into the determinants of HCE using aggregated data do not directly explore the relation between population ageing, LE and HCE. In this study, we will include the LE factor to re-estimate the population demographic effect on HCE in Taiwan during the period of 1960-2006.

We employ cointegration techniques to examine the long-run economic equilibrium between demographic factors, non-demographic factors and HCE. Our empirical results show that $\mathrm{HCE}$, income, population ageing, $\mathrm{LE}$, and the number of practicing physicians have a statistically significant relationship in the long run. We find that LE from aged groups is significantly and negatively related to HCE. The result is consistent with the time-to-death hypothesis, suggesting that HCEs increase significantly as death approaches and decrease when lifespan extends, and that the effect of age is greatly reduced when adding the time to death factor. ${ }^{12}$ Our findings strongly support the compression of morbidity, which assumes that older people have longer LE and improved health status. When these elderly reach the natural limits of longevity, their period of sickness gets compressed into a shorter period before death. ${ }^{13}$ We reason that the lengthening of LE can possibly reduce the growth in HCE. This finding is obviously of significance for health service policymakers and financial planners.

The paper is organised as follows. In the next section, we present the hypotheses concerning the impact of population ageing and LE on HCE. The subsequent section describes our data and methodology. In the penultimate section, we discuss the empirical results. The conclusions and policy implications are provided at the end of this paper.

\footnotetext{
${ }^{11}$ Lubitz et al. (2003).

12 Stearns and Norton (2004).

${ }^{13}$ Fries (1980).
} 


\section{Population ageing, life expectancy and health care expenditure}

Population ageing has become or is becoming a medical and social problem in most developed countries. Over 80 per cent of all illness, morbidity, mortality and medical costs are concentrated in the years after age 65 . The illness burden is mostly made up of chronic illness, complicated by the frailty of increasing age. ${ }^{14}$ The elderly thus use more health services and expenditure than the people under age 65. Chang et al. ${ }^{15}$ show that HCE is concentrated on a small population group in Taiwan's National Health Insurance system, with the highest users, although only 20 per cent of the enrollee population, accounting for 75 per cent of the spending. In Table 1, we find the group of population aged 65 and over is the highest user; their per capital HCE is about 4 to 6 times higher than other age groups for 0-14 and 15-65 years. Besides, the proportion of the population aged 65 and over has been growing year by year from 8 to 10 per cent during 1998-2006. Figure 2 displays the profiles of personal HCE in Taiwan by age group in 2006. As expected, expenditures increase with age and follow a $J$ curve, and this explains the concern that an ageing population will increase HCE. Unfortunately we cannot find enough empirical evidence in prior investigations to support this contention. We suppose that this previous research possibly omitted some demographic variables when estimating the impact of population ageing on HCE, causing a serious bias in the HCE regression model.

LE is a statistical measure of the average lifespan of a specific population. For advanced age groups, LE is more like the expectant time to death which is affected most strongly by changes in morbidity and health status. Stearns and Norton ${ }^{16}$ indicate that neglecting time to death when considering these issues may be viewed as an omitted variable problem that results in an upward bias on the estimated effect of age. With the time-to-death hypothesis, a shift in the mortality risk to higher ages will not affect lifetime HCE as a death occurs only once in every life. ${ }^{17}$ If most people spend a certain amount of money in their last year, the time to death is more important than calendar age when we examine the determinant of health expenditure. Disregarding the effects of increasing longevity on HCE, we perhaps overestimate the impact of population ageing on future expenditure.

Economic development brings medical progress, a fall in mortality, an increase in chronic disease and a lengthening of normal lifespan. Regarding the health of the elderly, there have been several hypotheses to explain the impact of changes in mortality, morbidity, disability and LE on HCE. In addition to the expansion and compression of morbidity hypotheses, the third hypothesis is the dynamic equilibrium proposed by Manton, ${ }^{18}$ which claims that mortality reductions will be associated with a redistribution of disease and disability. Thus, while the proportion of the lifespan with serious illness or disability stabilises or decreases, the proportion with moderate

\footnotetext{
${ }^{14}$ Fries (2000).

${ }^{15}$ Chang et al. (2002).

${ }^{16}$ Stearns and Norton (2004).

${ }^{17}$ Breyer and Felder (2006).

${ }^{18}$ Manton (1982).
} 
Table 1 Population and health care expenditure by three special age groups

\begin{tabular}{|c|c|c|c|c|c|c|c|c|c|}
\hline \multirow[b]{2}{*}{ Age groups } & \multicolumn{3}{|c|}{ Rates of HCE (\%) } & \multicolumn{3}{|c|}{ Rates of population (\%) } & \multicolumn{3}{|c|}{ Per capita HCE (NT\$) } \\
\hline & $0-14$ & $15-64$ & $65+$ & $0-14$ & $15-64$ & $65+$ & $0-14$ & $15-64$ & $65+$ \\
\hline 1998 & 13.46 & 64.12 & 26.77 & 21.96 & 69.79 & 8.26 & 8,045 & 13,194 & 44,024 \\
\hline 2002 & 12.22 & 63.06 & 29.40 & 20.42 & 70.56 & 9.02 & 8,990 & 14,181 & 51,822 \\
\hline 2006 & 9.60 & 60.66 & 33.32 & 18.12 & 71.88 & 10.00 & 10,357 & 16,773 & 69,357 \\
\hline
\end{tabular}

Source: TWDOH (2008) and own calculations.

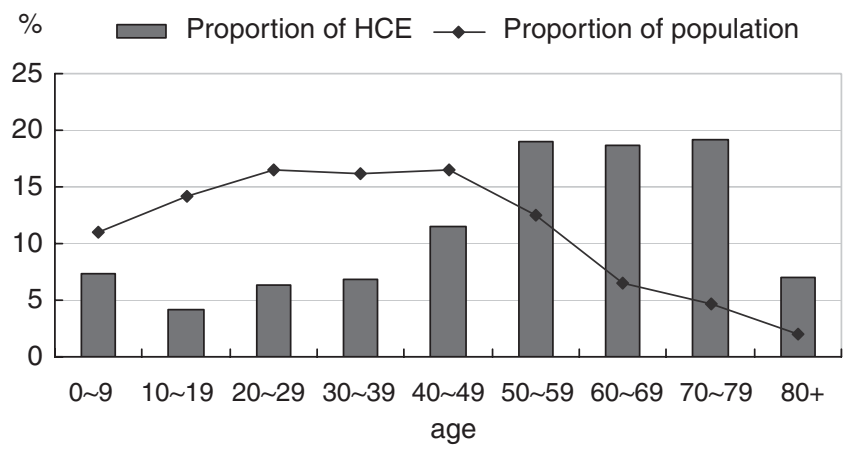

Figure 2. The Taiwan per capita health care expenditure by age group in 2006. Source: TWDOH (2008) and own calculations.

disability or less severe illness increases. Building on these earlier hypotheses, Michel and Robine ${ }^{19}$ proposed a new theory of the ageing population to suggest how the expression and compression of morbidity may co-exist today and in the future. For health insurance systems and policymakers, it is obviously important to analyse which of these scenarios is unfolding, along with the associated impact on HCE.

In this study, we emphasise the impact of longevity on HCE with an ageing population, aiming to examine whether longer life expectancies will increase or decrease HCE. This study differs from the earlier literature in that it adds factors related to longevity to re-estimate the population demographic effect on HCE. We use the LE at specific ages to proxy the time-to-death variable in order to find the relationship with HCE. First, on the basis of the time-to-death hypothesis, we assume that there possibly exists a negative relationship between LE and HCE. Second, we want to investigate whether the increase in LE would aggravate or mitigate the growth of HCE. If we find a negative impact on HCE, it will imply that the compression of morbidity is happening in Taiwan. Medical expenditure on the senior population may be reduced by their better health status and healthier lifestyles. In

\footnotetext{
${ }^{19}$ Michel and Robine (2004).
} 
contrast with prior studies, we are interested in the correlation between population ageing, LE and HCE. With the use of cointegration analysis, we attempt to estimate the impact of population ageing and LE on HCE in the long term, and to investigate whether there is compression or expansion of morbidity in Taiwan.

\section{Data and methodology}

In the previous studies, the main determinants of HCE were personal income, population ageing, technological change and other supply variables of medical services. This paper re-estimates the long-run economic relationship between HCE and related demographic variables, using time-series data in Taiwan during the period 1960-2006. In this data, the HCE and the income proxy, which is gross domestic product (denoted as GDP), are expressed in real per capita terms, with prices expressed in 2001 terms. For the choice of demographic variables, we are concerned that omitting the time-to-death variable will raise the bias on the estimated effect of age, ${ }^{20}$ and that if the LE of the aged population is increasing, this bias would increase over time. For this reason, we take the LE at specific ages as a time-to-death proxy in the aggregated model of HCE.

We thus separate the demographic effect into two aspects, population ageing and LE. With regard to the distribution of the aged population, we use the dependency ratio of the elderly population (denoted as AGE) to be the population ageing proxy, as in Chou. ${ }^{21}$ Following the demographic statistics definition, the aged dependency ratio is equal to the number of individuals aged over 65 divided by the number of individuals aged 15-64, expressed as a percentage. We choose three specific age groups from 65 to 79 , with every 5 years classified as one group, to estimate the impact of LE. The LE proxy for the age group 65-69 is denoted as LE65, the LE at the age group 70-74 is denoted as LE70, and the LE at the age group 75-79 is denoted as LE75.

In addition to these income and demographic variables, we also add other variables for the supply side, like the number of physicians per thousand persons (denoted as DR). Despite the claims of previous studies that technological innovation is of great significance in medical care, ${ }^{22}$ there is still little research that actually measures the potential contribution of technology to rising health care costs. It is thus a difficult task to find an appropriate proxy to measure these, due to lack of related data. ${ }^{23}$ Consequently, in this study, we focus only on demographic variables and do not deal with the problem of technological change and we do the same with the existing empirical research on this topic in Taiwan. ${ }^{24}$ To sum up the above, all the variables and definitions used in this work are given in Table 2.

\footnotetext{
${ }^{20}$ Stearns and Norton (2004).

${ }^{21}$ Chou (2007).

${ }^{22}$ Zweifel (1984); Berndt et al. (2000); Okunade and Murthy (2002).

23 Ahern (1993).

${ }^{24}$ Chiang (2002); Chen and Chiu (2003); Lin (2006).
} 
Table 2 Variables and definitions of regression

\begin{tabular}{ll}
\hline Variable & Definition \\
\hline HCE & Real per capital personal health care expenditures \\
GDP & Real per capital gross domestic product \\
AGE & Dependency ratio of the old-aged population \\
LE65 & Life expectancy for population aged $65-69$ years \\
LE70 & Life expectancy for population aged $70-74$ years \\
LE75 & Life expectancy for population aged $75-79$ years \\
DR & Number of practicing physicians per hundred thousand persons
\end{tabular}

We use the Johansen ${ }^{25}$ and Johansen and Juselius ${ }^{26}$ maximum likelihood procedure to capture the long-run quantitative impact of changes in GDP, AGE, LE, LEC, and DR on HCE variation. In the cointegration process, we use two tests, the maximal eigenvalue and trace tests, to determine the number of cointegrating vectors and longrun equilibrium relationships. For the potential endogeneity bias, we use two biascorrection methods, dynamic ordinary least squares (DOLS) and fully modified (FM) OLS, to deal with the endogeneity and serial dependence of regressors, as in Okunade and Murthy ${ }^{27}$ and Chou. ${ }^{28}$

Our study uses the annual macroeconomic data in Taiwan over the period from 1960 to 2006. The major sources for HCE, GDP, DR and related demographic data are obtained from the Taiwan national statistical information web site database, ${ }^{29}$ and all the variables in our model are expressed in natural logarithmic form.

\section{Empirical results}

Most macroeconomic time series seem to exhibit strong trends and so are not stationary and are therefore inappropriate for use in OLS estimation. ${ }^{30}$ In order to avoid spurious regressions and meaningless results, the texts on time series econometrics $^{31}$ have highlighted the importance of testing time-series data for the presence of a unit root. The unit root test results are presented in Table A1 of Appendix 1. We investigate the presence of the unit root in the level variables, HCE, GDP, AGE, LC65, LC70 and LC75. Accounting the unit root test results, we find all variables are obviously non-stationary in level but stationary in first differences, I(1), at a 5 per cent level of significance. We then use the cointegration procedure to examine the long-run relationship between the variables.

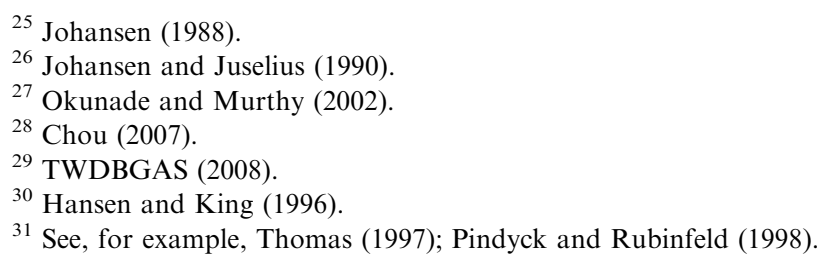


Our study is especially interested in the change of LE among three different groups of aged people, and the impact on HCE. We use four regressions to separately re-estimate the long run relationship between HCE, GDP, AGE, LE65, LE70, LE75 and DR, as shown below.

$$
\begin{aligned}
\text { Model I : } H C E_{t}= & \beta_{1}+\beta_{11} G D P_{t}+\beta_{12} A G E_{t} \\
& +\beta_{13} L E 65_{t}+\beta_{14} L E 70_{t}+\beta_{15} L E 75_{t} \\
& +\beta_{16} D R_{t}+\mu_{1 t} \\
\text { Model II }: H C E_{t}= & \beta_{2}+\beta_{21} G D P_{t}+\beta_{22} A G E_{t} \\
& +\beta_{23} L E 65_{t}+\beta_{24} D R_{t}+\mu_{2 t} \\
\text { Model III :HCE }= & \beta_{3}+\beta_{31} G D P_{t}+\beta_{32} A G E_{t} \\
& +\beta_{33} L E 70_{t}+\beta_{34} D R_{t}+\mu_{3 t} \\
& \\
\text { Model IV :HCE }= & \beta_{4}+\beta_{41} G D P_{t}+\beta_{42} A G E_{t} \\
& +\beta_{43} L E 75_{t}+\beta_{44} D R_{t}+\mu_{4 t}
\end{aligned}
$$

Table A2 of Appendix 2 shows the cointegration tests results for Models I-IV using the cointegration approach. We report the normalised cointegration vectors of Models I-IV in Table 3. Following the single cointegration vector tests, we obtain three cointegrated regressions to estimate the demographic impact on $\mathrm{HCE}$, as in equations (5)-(7).

$$
\begin{aligned}
& H C E_{t}=-10.17+0.98 G D P_{t}(-7.06) \\
&+0.27 A G E_{t}(-6.15)-6.53 L E 65_{t}(4.18) \\
&+0.88 D R_{t}(-3.95) \\
& E T C=-1.18(-3.18) \\
& H C E_{t}=-9.41+1.01 G D P_{t}(-7.62)+0.37 A G E_{t}(-7.09) \\
&-7.04 L E 70_{t}(6.02)+0.61 D R_{t}(-2.67) \\
& H C E_{t}=-5.36+0.97 G D P_{t}(-6.80)+0.39 A G E_{t}(-6.41) \\
&-5.93 L E 70_{t}(5.77)+0.46 D R_{t}(-1.72) \\
& E T C=-0.11(-2.32)
\end{aligned}
$$

The observed asymptotic $t$-values are shown in parentheses. We find the errorcorrection terms (ECT) are highly significant with the expected negative sign, and for equations (5) to ( 7 ) are $-1.18,-0.15$, and -0.11 , respectively. Those highly significant and negative ECT support the validity of a long-run equilibrium relationship among HCE, GDP, AGE, DR and the related LE variables. Furthermore, the coefficients of GDP, AGE and DR are significant and positive at the 1 per cent level. These results conform to the past empirical results on the determination of HCE. The estimated 
Table 3 Normalised cointegration vector

\begin{tabular}{|c|c|c|c|c|c|c|}
\hline Variables & \multicolumn{2}{|c|}{ Model $I I^{\mathrm{a}}$} & \multicolumn{2}{|c|}{ Model $I I I^{\mathrm{b}}$} & \multicolumn{2}{|c|}{ Model VI } \\
\hline$H C E_{t}$ & \multicolumn{2}{|c|}{1} & \multicolumn{2}{|c|}{1} & \multicolumn{2}{|c|}{1} \\
\hline$G D P_{t}$ & -0.98 & $(-7.06)^{* *}$ & -1.01 & $(-7.62)^{* *}$ & -0.97 & $(-6.80)^{* *}$ \\
\hline$A G E_{t}$ & -0.27 & $(-6.15)^{* *}$ & -0.37 & $(-7.09)^{* *}$ & -0.39 & $(-6.41)^{* *}$ \\
\hline$L E 65_{t}$ & 6.53 & $(4.81)^{* *}$ & & & & \\
\hline$L E 70_{t}$ & & & 7.04 & $(6.02)^{* *}$ & & \\
\hline$L E 75_{t}$ & & & & & 5.93 & $(5.77)^{* *}$ \\
\hline$D R_{t}$ & -0.88 & $(-3.95)^{* *}$ & -0.61 & $(-2.67)^{* *}$ & -0.46 & $(-1.72)$ \\
\hline $\mathrm{C}$ & -10.17 & & -9.41 & & -5.36 & \\
\hline Error-correction & -1.18 & $(-3.18)^{* *}$ & -0.15 & $(-2.09)^{*}$ & -0.11 & $(-2.32)^{*}$ \\
\hline
\end{tabular}

Notes: All variables are in natural logarithms; and figures in parentheses are $t$-statistics.

*Denotes statistical significant at the 5 per cent level. ${ }^{* *}$ Denotes statistical significant at the 1 per cent level.

${ }^{a}$ Residuals from for Model I: $\mu_{1 t}=[H C E, G D P, A G E, L E 65, L E C 65, D R]\left[1,-\beta_{11},-\beta_{12},-\beta_{13},-\beta_{14},-\beta_{15}\right]^{\prime}$

${ }^{\mathrm{b}}$ Residuals from for Model II: $\mu_{2 t}=[H C E, G D P, A G E, L E 70, L E C 70, D R]\left[1,-\beta_{21},-\beta_{22},-\beta_{23},-\beta_{24},-\beta_{25}\right]^{\prime}$

coefficient of GDP as the long run income elasticity of health demand is between 0.97 and 1.01, meaning that health care at the aggregate level appears to be a necessity good. We can also find that the impact of population ageing is positive but small in every regression. As regards LE, we observed that the coefficients of LE65, LE70 and LE75 are significant and negative in the long run. The expected remaining life, or the time to death, is the major determinant of health care costs and thus the increase in LE would cause health expenditure to decrease. This implies that we do not need to worry that the expenditure will rise as the people become aged and live longer. On the other hand, the results support the compression of morbidity hypothesis, in that there is a negative relationship between the LE for the three aged groups and HCE. We use the restrictive function to test the coefficient restrictions of the vector error correction model. Based on the likelihood ratio $\left(\chi^{2}\right)$ exclusion test results, the vector coefficients of AGE, LE65 (or LE70, LE75), and DR are significant and equal to $(1,-1,1)$, respectively. The observed LR statistics $\left(\chi^{2}\right)$ of Models II-VI are all smaller than the $\chi^{2}$ critical value with two degrees of freedom with a 5 per cent statistical significance level, suggesting that we cannot reject the null hypothesis that the vector coefficients of AGE, LE65 (or LE70, LE75), and DR are significant and equal to $(1,-1,1)$, respectively, in Models II-IV. From the Johansen cointegration tests and the vector error correction model, we find that HCE, AGE, LE65 (or LE70, LE75) and DR have an equilibrium relationship in the long run.

Following the methods in Chou, ${ }^{32}$ we use DOLS and FMOLS to deal with the endogenous problem of the cointegration regressions outlined above. Prior studies ${ }^{33}$ have argued that the DOLS estimator outperforms the OLS and FMOLS. Table 4 shows the estimated long-run elasticity of Models II-IV based on the conventional OLS, DOLS, and FMOLS methods, along with their corresponding $t$-values.

\footnotetext{
${ }^{32}$ Chou (2007).

33 e.g., Kao and Chiang (2000).
} 
Yung-Ming Shiu and Mei-Ching Chiu

Table 4 Using OLS, DOLS, and FMOLS methods to estimate Models II-VI (dependent variable: HCE)

\begin{tabular}{|c|c|c|c|c|c|c|c|}
\hline \multirow{2}{*}{$\begin{array}{l}\text { Model } \\
\text { Model II }\end{array}$} & \multirow{2}{*}{$\begin{array}{l}\text { Variables } \\
G D P_{t}\end{array}$} & \multicolumn{2}{|c|}{$O L S$} & \multicolumn{2}{|c|}{$D O L S$} & \multicolumn{2}{|c|}{$F M O L S$} \\
\hline & & 0.34 & $(5.11)^{* *}$ & 0.15 & $(3.26)^{* *}$ & 0.21 & $(1.71)^{*}$ \\
\hline & $A G E_{t}$ & 0.29 & $(11.33)^{* *}$ & 0.07 & $(2.08)^{*}$ & 0.27 & $(7.09)^{* *}$ \\
\hline & $L E 65_{t}$ & -0.78 & $(-1.11)$ & -0.91 & $(-2.06)^{*}$ & -0.08 & $(-1.14)$ \\
\hline & $D R_{t}$ & 0.01 & $(0.10)$ & 0.20 & $(2.52)^{*}$ & 0.14 & $(0.85)$ \\
\hline & $\mathrm{C}$ & 1.09 & $(0.74)$ & 1.49 & $(2.95)^{* * *}$ & 0.03 & $(0.07)$ \\
\hline & $R$-squared & 0.99 & & 0.99 & & 0.98 & \\
\hline & D.W. & 0.51 & & 1.58 & & 1.17 & \\
\hline \multirow[t]{7}{*}{ Model III } & $G D P_{t}$ & 0.31 & $(5.18)^{* *}$ & 0.12 & $(5.18)^{* *}$ & 0.19 & $(2.42)^{*}$ \\
\hline & $A G E_{t}$ & 0.28 & $(9.11)^{* *}$ & 0.06 & $(9.11)^{* *}$ & 0.26 & $(6.39)^{* *}$ \\
\hline & $L E 65_{t}$ & -0.26 & $(-0.48)$ & -0.50 & $(-2.18)^{*}$ & -0.24 & $(-1.69)$ \\
\hline & $D R_{t}$ & 0.01 & $(0.02)$ & 0.17 & $(2.16)^{*}$ & 0.14 & (1.06) \\
\hline & $\mathrm{C}$ & 0.01 & $(-0.01)$ & 0.55 & $(2.91)^{* * *}$ & 0.11 & $(1.34)$ \\
\hline & $R$-squared & 0.99 & & 0.99 & & 0.98 & \\
\hline & D.W. & 0.48 & & 1.52 & & 1.25 & \\
\hline \multirow[t]{7}{*}{ Model VI } & $G D P_{t}$ & 0.29 & $(5.47)^{* *}$ & 0.11 & $(2.65)^{* *}$ & 0.19 & $(1.45)$ \\
\hline & $A G E_{t}$ & 0.27 & $(11.87)^{* *}$ & 0.06 & $(1.62)^{* *}$ & 0.25 & $(6.39)^{* *}$ \\
\hline & $L E 65_{t}$ & -0.09 & $(-1.92)$ & -0.32 & $(-2.04)^{*}$ & -0.26 & $(-0.76)$ \\
\hline & $D R_{t}$ & 0.01 & $(0.05)$ & 0.17 & $(2.24)^{*}$ & 0.14 & (0.96) \\
\hline & $\mathrm{C}$ & -0.35 & $(1.42)$ & 0.15 & $(0.32)$ & -0.10 & $(-0.47)$ \\
\hline & $R$-squared & 0.99 & & 0.99 & & 0.97 & \\
\hline & D.W. & 0.47 & & 1.51 & & 1.26 & \\
\hline
\end{tabular}

Notes: All variables are in natural logarithms; and figures in parentheses are $t$-statistics.

*Denotes statistical significance at the 5 per cent level; **Denotes statistical significance at the 1 per cent level.

Consequently, we can make the following observations. First, the OLS estimators of the LE65, LE70, LE75, and DR have no statistical significance in Models II-VI, but they all have regression biases because the $R$-squared value is greater than the DW value in the OLS model. As Granger and Newbold have suggested, if the $R$-squared value is larger than the DW value, that is a good rule of thumb to suspect that the estimated regression is spurious. ${ }^{34}$ Therefore, we find that the OLS method is not suitable to estimate the relationship between $\mathrm{HCE}$ and other macroeconomics variables. Second, the DOLS and FMOLS estimates of GDP, AGE, and DR have positive coefficients and LE65, LE70, and LE75 on HCE have negative effects. Only the bias correction estimates of DOLS indicate that LE has a significant impact on HCE. As Kao and Chiang ${ }^{35}$ have pointed out, the FMOLS estimator could be inferior to the conventional OLS in some cases, and so we make our conclusion based on the DOLS estimates. We calculate that the income, dependency ratio of the old age population and the number of practicing physicians have significant positive impacts on HCE. With regard to the elderly, we suggest that LE has a negative influence on HCE. In line with the compression of morbidity hypothesis, the morbidity is

\footnotetext{
${ }^{34}$ Gujarati (2006).

${ }^{35}$ Kao and Chiang (2000).
} 
compressed and the average illness burden is reduced, the remaining life is prolonged, life quality is improved and the need for medical care and associated costs may be cut. ${ }^{36}$ We thus find a long-term relationship between demographics and HCE, and assume that the extension of lifespan would slow down the growth rate of health care cost in Taiwan.

\section{Conclusion and policy implications}

In this paper we re-estimate the demographic impact on HCE during the period of 1960-2006 in Taiwan. In addition to population ageing, we especially add LE from advanced ages to examine the demographic impact on HCE. The results are robust to a battery of unit root and cointegration tests, and we find that $\mathrm{HCE}$, income, population ageing, LE and the number of practicing physicians have statistic significance and long-term economic relationship in Taiwan. Our data shows population ageing, proxied by the dependency ratio, has a significantly positive but weak impact on HCE. The LE at the age groups of 65, 70, and 75 has a significantly negative impact on HCE and the coefficient becomes smaller as the age level rises. Our results thus support the compression of morbidity hypothesis. Longevity and population ageing do not inevitably lead to an increase in HCE. People possibly have more healthy LE at the advanced ages.

The conventional wisdom is that health care costs increase with an ageing population. However, this ageing was not found to be a significant factor in explaining the variations of HCE in prior research, ${ }^{37}$ although this might be due to the problem of omitting a variable. After taking into account LE at various advanced ages, we find that population ageing, proxied by the dependency ratio, does have a positive impact on HCE. This finding is consistent with Chou. ${ }^{38}$

Consistent with the compression of morbidity hypothesis, our findings indicate that if people live longer and more healthily then the effect of ageing on health costs may be offset by that of LE, which is likely to have meaningful implications for policymaking and future research. If the extension of LE is due to good life style and health status, the authorities concerned should consider enhancing public education to improve health, and so we do not necessarily need to worry about the adverse impact on health expenditure as LE increases. One of the limitations of this study is that LE represents the length of life prior to death, but does not measure the quality of life and health status. The World Health Organization proposed a general model of health transition to evaluate the consequences of an increase in survival of health status in $1984 .{ }^{39}$ This model calculates not only ordinary LE, but also disease-free/disability-free LE. ${ }^{40}$ Future research could use the disability-adjusted LE data to more accurately estimate

\footnotetext{
${ }^{36}$ Fries (2000).

${ }^{37}$ See, for example, Newhouse (1977); Gerdtham et al. (1992); Hitiris and Posnett (1992); Zweifel et al. (2004).

38 Chou (2007).

${ }^{39}$ Michel and Robine (2004).

${ }^{40}$ WHO (1984).
} 
the impact of healthy LE on HCE. On the other hand, different diseases may have different effects on the morbidity compression, and future research should use individual disease data to investigate the existence of morbidity compression in Taiwan.

\section{References}

Ahern, M. (1993) 'The softness of medical production and implications for specifying hospital outputs', Journal Economic Behavior and Organization 20: 281-294.

Barros, P.P. (1998) 'The black box of health care expenditure growth determinants', Health Economics 7 : 533-544.

Berndt, E.R., Cutler, D.M., Frank, R.G., Griliches, Z., Newhouse, J.P. and Triplett, J. (2000) Medical Prices and Output, Handbook of Health Economics, Amsterdam: North Holland, pp. 119-180.

Breyer, F. and Felder, S. (2006) 'Life expectancy and health care expenditures: A new calculation for Germany using the costs of dying', Health Policy 75: 178-186.

Chang, H.J., Huang, S.C. and Chiang, T.P. (2002) 'Concentration of health care expenditures in Taiwan analysis of patient's characteristics', Taiwan Journal of Public Health 21: 207-213.

Chen, S.N. and Chiu, Y.L. (2003) 'Determinants of national health care expenditure: A time series and threshold model approach', Taipei Economic Inquiry 39: 197-240.

Chiang, T.L. (2002) 'Analysis on trends for healthcare expenditures in Taiwan', Taiwan Journal of Public Health 21: 157-163.

Chou, W.L. (2007) 'Explaining China's regional health expenditures using lm-type unit root tests', Journal of Health Economics 26: 682-698.

Daviglus, M.L., Liu, K. and Greenl, P. (1998) 'Benefit of a favorable cardiovascular risk factor profile in middle age with respect to Medicare costs', New England Journal of Medicine 339: 1122-1129.

Di Matteo, L. (2005) 'The macro determinants of health expenditure in the United States and Canada: Assessing the impact of income, age distribution and time', Health Policy 71: 23-42.

Dickey, D.A. and Fuller, W.A. (1979) 'Distribution of the estimators for autoregressive time-series with a unit root', Journal of the American Statistical Association 74: 427-431.

Dormont, B., Grignon, M. and Huber, H. (2006) 'Health expenditure growth: Reassessing the threat of ageing', Health Economics 15: 947-963.

Fries, J.F. (1980) 'Aging, natural death, and the compression of morbidity', New England Journal of Medicine 303: 130-135.

Fries, J.F. (2000) 'Compression of morbidity in the elderly', Vaccine 18: 1584-1589.

Gerdtham, U.G. and Lothgren, M. (2000) 'On stationarity and cointegration of international health expenditure and GDP', Journal of Health Economics 19: 461-475.

Gerdtham, U.G., Sogaard, J., Andersson, F. and Jonsson, B. (1992) 'An econometric analysis of health care expenditure: A cross-section study of the OECD countries', Journal of Health Economics 11: 63-84.

Gujarati, D.N. (2006) Essentials of Econometrics, 3rd edn, Singapore: McGraw-Hill Education (Asia).

Hansen, P. and King, A. (1996) 'The determinants of health care expenditure: A cointegration approach', Journal of Health Economics 15: 127-137.

Hitiris, T. and Posnett, J. (1992) 'The determinants and effects of health expenditure in developed countries', Journal of Health Economics 11: 173-181.

Hodgson, T.A. (1992) 'Cigarette smoking and lifetime medical expenditures', Milbank Quarterly 70: $81-125$.

Johansen, S. (1988) 'Statistical analysis of cointegrated vectors', Journal of Economic Dynamics and Control 12: $231-254$.

Johansen, S. and Juselius, K. (1990) 'Maximum likelihood estimation and inference on cointegration with applications to demand for money', Oxford Bulletin of Economics and Statistics 52: 169-210.

Kao, C. and Chiang, M. (2000) Advances in Econometrics, Amsterdam: Elsevier Science, pp. 179-222.

Kwiatkowski, D., Phillips, P.C.B., Schmidt, P. and Shin, Y. (1992) 'Testing the null hypothesis of stationarity against the alternative of a unit root: How sure are we that economic time-series have a unit root?', Journal of Econometrics 54: 159-178. 
740

Lin, P.W. (2006) 'An exploration on factors associated with the growth of health care expenditure in Taiwan: 1981-2003', Journal of Healthcare Management 7: 429-446.

Lubitz, J., Cai, L., Kramarow, E. and Lentzner, H. (2003) 'Health, life expectancy, and health care spending among the elderly', New England Journal of Medicine 349: 1048-1055.

Manton, K.G. (1982) 'Changing concepts of morbidity and mortality in the elderly population', Milbank Memorial Fund Quarterly, Health and Society 60: 183-244.

Martins, O., Joaquim, C.M. and Bjornerud, S. (2006) Projecting OECD Health and Long-term Care Expenditures: What are the Main Drivers, Economics Department Working Papers, OECD, Paris.

Michel, J.P. and Robine, J.M. (2004) 'A new general theory of population ageing', The Geneva Papers on Risk and Insurance - Issues and Practice 29: 667-678.

Miller, T. (2001) 'Increasing longevity and Medicare expenditures', Demography 38: 215-226.

Murthy, N.R.V. and Ukpolo, V. (1994) 'Aggregate health care expenditure in the United States: Evidence from cointegration tests', Applied Economics 26: 797-802.

Murthy, N.R.V. and Ukpolo, V. (1995) 'Aggregate health care expenditure in the United States: New results', Applied Economics Letters 2: 419-421.

Newhouse, J.P. (1977) 'Medical-care expenditure: A cross-national survey', Journal of Human Resources 12: 115-125.

O'Connell, J. (1996) 'The relationship between health expenditures and the age structure of the population in OECD countries', Health Economics 5: 573-578.

Okunade, A.A. and Murthy, V.N.R. (2002) "Technology as a "Major Driver" of health care costs: A cointegration analysis of the newhouse conjecture', Journal of Health Economics 21: 147-159.

Pantula, S.G. (1989) 'Testing for unit roots in time-series data', Econometric Theory 5: 256-271.

Phillips, P. and Perron, P. (1988) 'Testing for a unit root in time-series regression', Biometrica 75: 335-346.

Pindyck, R.S. and Rubinfeld, D.L. (1998) Econometric Models and Economic Forecasts, New York: McGraw-Hill.

Ryder, N.B. (1988) Effects on the Family of Changes in the Age Distribution, Proceedings of the International Symposium on Population Structure and Development, New York: UN Department of International Economic and Social Affairs, pp. 98-120.

Seshamani, M. and Gray, A.M. (2004) 'A longitudinal study of the effects of age and time to death on hospital costs', Journal of Health Economics 23: 217-235.

Spillman, B.C. and Lubitz, J. (2000) 'The effect of longevity on spending for acute and long-term care', New England Journal of Medicine 342: 1409-1415.

Stearns, S.C. and Norton, E.C. (2004) 'Time to include time to death? The future of health care expenditure predictions', Health Economics 13: 315-327.

Thomas, R.L. (1997) Modern Econometrics, Upper Saddle River, NJ: Addison-Wesley Longman.

TWCEPD (Taiwan Council for Economic Planning and Development) (2008) 'Taiwan population estimation report during 2006 to 2051', from http://www.cepd.gov.tw/, accessed January 2008.

TWDBGAS (Taiwan Directorate-General of Budget, Accounting and Statistics) (2008) 'National Statistics', from http://www.stat.gov.tw/, accessed January 2008.

TWDOH (Taiwan Department of Health) (2008) 'Health and National Health Insurance Annual Statistics Information Service', from http://www.doh.gov.tw/statistic/index.htm, accessed January 2008.

UNPD (2006) World Population Prospects: The 2006 Revision and World Urbanization Prospects, Geneva: Population Division of the Department of Economic and Social Affairs of the United Nations Secretariat.

WHO (1984) The uses of epidemiology in the study of the elderly, World Health Organization technical report series 706, Geneva.

Zweifel, P. (1984) 'Technological change in health care: Why are opinions so divided?', Managerial and Decision Economics 5: 177-182.

Zweifel, P., Felder, S. and Meiers, M. (1999) 'Ageing of population and health care expenditure: A red herring?', Health Economics 8: 485-496.

Zweifel, P., Felder, S. and Werblow, A. (2004) 'Population ageing and health care expenditure: New evidence on the red herring', The Geneva Papers on Risk and Insurance - Issues and Practice 29: 652-666. 


\section{Appendix 1}

Unit root tests of the type suggested by Dickey and Fuller, ${ }^{41}$ and Phillips and Perron ${ }^{42}$ have become part of the exploratory data analysis for time series models. Consequently, when dealing with cointegration processes, we require that the timeseries data be first tested for the presence of unit roots in the level series as well as in first differences. In this paper, we use the common unit root tests, the augmented Dickey and Fuller (hereafter ADF), the Phillips and Perron (hereafter PP) and the KPSS $^{43}$ tests, for all the variables in natural logarithms form in their levels and first differences. The ADF and PP have similar tests to specify the null hypothesis of nonstationarity. The primary difference between the two is that the ADF test assumes that the errors are independent and homogeneous, while the PP test accommodates autocorrelated errors by using a non-parametric correlation. ${ }^{44}$ Because the KPSS test has the opposite null hypothesis to the ADF test, we use the form to confirm whether all the variables become stationary on first differencing. Table A1 shows the results of unit root test for the variables.

Table A1 Unit root tests

\begin{tabular}{lcccccc}
\hline Variables & $A D F\left(\beta_{\mu}\right)^{\mathrm{a}}$ & $A D F\left(\beta_{\tau}\right)^{\mathrm{a}}$ & $P P\left(\beta_{\mu}\right)^{\mathrm{a}}$ & $P P\left(\beta_{\tau}\right)^{\mathrm{a}}$ & $K P S S\left(\beta_{\mu}\right)^{\mathrm{b}}$ & $K P S S\left(\beta_{\tau}\right)^{\mathrm{b}}$ \\
\hline$H C E_{t}$ & -0.17 & -3.30 & -0.03 & -1.67 & 0.87 & 0.16 \\
GDP $P_{t}$ & -2.44 & 6.33 & -2.23 & 0.22 & 0.89 & 0.20 \\
$A G E_{t}$ & -0.97 & -0.04 & -0.86 & -0.96 & 0.88 & 0.18 \\
$L E 65_{t}$ & -0.16 & -2.99 & 0.07 & -2.99 & 0.88 & 0.12 \\
$L E 70_{t}$ & -0.24 & -2.78 & -0.01 & -2.83 & 0.87 & 0.16 \\
$L E 75_{t}$ & -0.27 & -2.67 & -0.04 & -2.56 & 0.87 & 0.17 \\
$D R_{t}$ & 0.99 & -3.31 & 0.68 & -3.31 & 0.85 & 0.21 \\
$\Delta H C E_{t}$ & -5.00 & -3.78 & -5.25 & -5.23 & 0.13 & 0.11 \\
$\Delta G D P_{t}$ & -4.81 & -5.51 & -4.79 & -5.48 & 0.36 & 0.10 \\
$\Delta A G E_{t}$ & -4.25 & -4.33 & -4.34 & -4.41 & 0.21 & 0.13 \\
$\Delta L E 65_{t}$ & -9.34 & -9.31 & -9.25 & -9.52 & 0.10 & 0.09 \\
$\Delta L E 70_{t}$ & -7.79 & -7.76 & -8.68 & -9.16 & 0.13 & 0.13 \\
$\Delta L E 75_{t}$ & -7.12 & -7.09 & -7.77 & -8.56 & 0.14 & 0.06 \\
$\Delta D R_{t}$ & 4.21 & -4.31 & -4.39 & -4.49 & 0.28 & 0.13 \\
\hline
\end{tabular}

Notes: All variables are in natural logarithms); $\left(\beta_{\mu}\right)$ and $\left(\beta_{\tau}\right)$ are statistical test values, with intercept and with intercept and trend, respectively.

${ }^{\mathrm{a}}$ For ADF and PP tests, the 5 per cent critical value of $\beta_{\mu}$ is -2.93 and the 5 per cent critical value of $\beta_{\tau}$ is -3.52 .

${ }^{\mathrm{b}}$ For KPSS tests, the 5 per cent critical value of $\beta_{\mu}$ is 0.46 and the 5 per cent critical value of $\beta_{\tau}$ is 0.14 .

\footnotetext{
${ }^{41}$ Dickey and Fuller (1979).

42 Phillips and Perron (1988).

${ }^{43}$ Kwiatkowski et al. (1992).

${ }^{44}$ Hansen and King (1996).
} 


\section{Appendix 2}

Following the Pantula ${ }^{45}$ principle, we first determine the model with the cointegrating rank $(r)$ equal to 1 , and then all the variables have a long run equilibrium relationship in the regression. For example, if all the series are I(1) in Model I and only has one cointegrating vector, then it implies that all series have a cointegrated relation, and the cointegrating vector is equal to $\left[1,-\beta_{11},-\beta_{12},-\beta_{13},-\beta_{14},-\beta_{15}\right]$. Both the maximal eigenvalue and trace tests have the null hypothesis that there are $r$ cointegrating vectors. We use the maximal eigenvalue $\left(\lambda_{\max }\right)$ and trace tests to show that all variables in the model only have one economic relationship in the long run. As a result of cointegration tests, we find that deterministic components of Models II-IV have a single cointegrating vector at a 5 per cent significance level. By using the Johansen cointegration approach, we have three combinations to explain that there exists the long-run equilibrium relationship between HCE, GDP, AGE, LE, and DR for three different aged groups. The results of Johansen cointegration tests for Models I-IV are presented in Table A2.

Table A2 Johansen cointegration tests

\begin{tabular}{lllr}
\hline Model & $\gamma^{\mathrm{a}}$ & $\lambda_{\max }{ }^{\mathrm{a}}$ & Trace $^{\mathrm{a}}$ \\
\hline Model I & 0 & $69.97^{*}$ & $80.14^{*}$ \\
& 1 & $51.97^{*}$ & $44.21^{*}$ \\
& 2 & 28.17 & $19.06^{*}$ \\
Model II & & & $80.14^{*}$ \\
& 1 & $35.93^{*}$ & 44.21 \\
& 2 & 25.15 & 19.06 \\
Model III & & 12.41 & $87.30^{*}$ \\
& 0 & $40.55^{*}$ & 46.75 \\
& 1 & 25.66 & 21.09 \\
Model IV & 2 & 12.08 & $86.44^{*}$ \\
& & $40.16^{*}$ & $46.28^{*}$ \\
& 0 & 25.36 & 20.92 \\
\hline
\end{tabular}

Notes: All variables are in natural logarithms. ${ }^{*}$ Denotes rejection of the hypothesis at the 5 per cent level. ${ }^{\mathrm{a}}$ The numbers in columns two and three are test statistics; and parameter $r$ is the number of cointegrating relationships

\footnotetext{
${ }^{45}$ Pantula (1989)
} 


\begin{abstract}
About the Authors
Yung-Ming Shiu is Associate Professor in the Department of Business Administration at National Cheng Kung University, Taiwan. He teaches risk management and insurance. Dr. Shiu's research focuses on the areas of corporate hedging, risk management and insurance. His research has appeared in a number of scholarly and trade journals such as the Journal of Futures Markets and the British Actuarial Journal.

Mei-Ching Chiu is a Ph.D. student in the Department of Business Administration at National Cheng Kung University, Taiwan. She is also Lecturer in the Department of Digital Commerce at Kao Fong College, Taiwan. Ms. Chiu teaches economics and industry analysis. Her research focuses on the areas of health economics and health policy.
\end{abstract}

